\title{
The First Two Decades of Smart-City Research: A Bibliometric Analysis
}

Luca Mora ${ }^{a^{*}}$, Roberto Bolici ${ }^{b}$, Mark Deakin $^{c}$

${ }^{a}$ Politecnico di Milano, Department of Architecture, Built Environment and Construction Engineering, Via G. Ponzio 31, 20133 Milano, luca.mora@polimi.it

${ }^{b}$ Politecnico di Milano, Department of Architecture, Built Environment and Construction Engineering $(A B C)$

${ }^{c}$ Edinburgh Napier University, School of Engineering and Built Environment

* Corresponding author 


\section{The First Two Decades of Smart-City Research: A Bibliometric Analysis}

This paper reports on the first two decades of research on smart cities by conducting a bibliometric analysis of the literature published between 1992 and 2012. The analysis shows that smart city research is fragmented and lacks cohesion, and its growth follows two main development paths. The first one is based on the peer-reviewed publications produced by European universities, which support a holistic perspective on smart cities. The second path, instead, stands on the grey literature produced by the American business community and relates to a techno-centric understanding of the subject. Divided along such paths, the future development of this new and promising field of research risks being undermined. For while the bibliometric analysis indicates that smart cities are emerging as a fast-growing topic of scientific enquiry, much of the knowledge which is generated about them is singularly technological in nature. In that sense, lacking the social intelligence, cultural artifacts, and environmental attributes which are needed for the ICT-related urban innovation such research champions to be smart in securing the physical infrastructure requirements of cities.

Keywords: smart city research; urban innovation; bibliometric analysis; development paths; corporate model; holistic interpretation

\section{Introduction}

Cities are complex and highly organized systems, "a collection of elements that act independently of one another but nevertheless manage to act in concert". Their state of balance is extremely sensitive and subject to continuous changes dependent on "how we intervene in their organization through different forms of planning" (Batty and Marshall, 2009). The need to manage this difficult scenario has required the connection between many academic disciplines (Benevolo, 2011; Secchi, 2011) brought together in the unique field of urban studies (Liu, 2005), which is "one of the longest established interdisciplinary fields within the modern academy" (Kamalski and Kirby, 2012).

Computer science is one of these disciplines, and its continuous and progressive approach to urban studies started during the last years of the $20^{\text {th }}$ century, when the digital revolution began to transform urban areas "into a constellation of computers" (Batty, 1997). During this period, "many commentators seemed to suggest that the new frontier [of information technology] was to provide solutions for overcoming most spatial and social problems [and] cities looked like the ideal arena where this revolution would test and show itself, changing economic development, services, and above all, community life" (Firmino, 2003). In this scenario, the information and communication technologies (ICTs) of urban areas are innovations supporting a new science of cities (Batty, 2014).

The exploration of the relationship between ICTs and urban areas began with Graham and Marvin's "Telecommunications and the City" (Graham and Marvin, 1996). Along with the work produced by Mitchell (1995; 1999; 2003) and Castells (1996), their research activity has allowed this new area of knowledge to take shape and develop in a concrete form. This process of knowledge production has resulted in the publication of numerous scientific documents (see Graham and Marvin 1996; 1999; 2001; 2004 and Graham 1997; 2000; 2001; 2002; 2004a). Many of these publications can be considered the most influential resources in the cognitive structure of "urban ICT studies" (Graham, 2004b), a sub-discipline of urban studies in which research is 
carried out to study "the complex and poorly understood set of relationships between telecommunications and the development, planning and management of contemporary cities" (Graham and Marvin, 1996).

As an object of scientific enquiry, smart city studies fall in this research domain and first appeared in 1992 within the book entitled "The Technopolis Phenomenon: Smart Cities, Fast Systems, Global Networks" (Gibson et al., 1992). Over the years, smart cities have become the symbol of ICT-driven urban innovation and development, and started to attract the increasing attention of many researchers from universities, governments, and businesses. Thanks to their interest, smart city research has been growing sharply. Evidence of this trend can be found by analyzing Google Scholar's data. Following a request to identify the literature produced between 1992 and 2015 in which the term smart city is included in the singular or plural form, the scholarly engine developed by Google has sourced 25,770 documents $^{1}$. Data shows that the annual production of publications on smart cities has increased by 600 times within 24 years, moving from 16 in 1992 to 9,494 in $2015^{2}$.

The exploratory study reported on in this paper aims to provide an overall and detailed picture of what happened during the first two decades of research on smart cities, and lead to an improved understanding of the origins and progressive evolution of this fast-emerging research area and its intellectual structure. This aim is achieved by answering the following research questions:

- What are the characteristics of the literature produced during the period 19922012 in terms of type, influence, and impact?

- How large was the scientific community researching smart cities?

- What are the influence and productivity levels of researchers falling within this community and the organizations to which they belong?

- What is the interpretation of the smart city concept that emerges from their research?

- What factors have influenced the development of the intellectual structure resulting from the first two decades of smart city research?

To answer these questions, bibliometric analysis techniques are used to analyze both the literature on smart cities published between 1992 and 2012, and the community of researchers involved in its production. The methodology used to perform the analysis is illustrated in Section 2 of the paper. This is followed by an in-depth description of the findings which sheds light on the first 20 years of research in the field of smart cities (Section 3). These findings are then discussed in relation to the content of the smart city literature produced subsequent to the period under investigation (Section 4). The paper concludes with some recommendations aimed at guiding future research on smart cities in line with the findings reported on (Section 5).

\section{Bibliometrics and the analysis of knowledge domains}

Bibliometrics investigates the formal properties of knowledge domains by using mathematical and statistical methods (Pritchard, 1969; Ding et al., 2001; Godin, 2006; De Bellis, 2009). Interest in applying these methods to explore the development of smart cities as a knowledge domain has grown considerably over the past 5 years and has resulted in the production of the following publications:

- Durán-Sánchez et al. (2017): description of scientific research on smart cities by way of a bibliometric analysis and through a review of the literature indexed in Web of Science and Elsevier's Scopus databases;

- Ojo et al. (2016): examination of the smart city knowledge domain using Scopus' journal articles and conference papers related to both smart cities and intelligent cities, which the authors consider equivalent terms;

- Tregua et al. (2015): analysis of the relationship between sustainable and smart 
cities using 367 journal articles and books indexed in Web of Science;

- Ricciardi and Za (2015): examination of about 100 documents stored in the websites of two international conferences on smart cities "to define the boundaries of smart city research and to draw a map of [its] interdisciplinary community";

- de Jong et al. (2015): identification of the conceptual differences and relationships between twelve dominant city categories (sustainable city, eco city, low carbon city, liveable city, green city, smart city, digital city, ubiquitous city, intelligent city, information city, knowledge city, resilient city). This study is conducted by way of a bibliometric analysis and through the academic literature retrieved from Web of Science and Scopus.

What these studies have in common is a tendency to focus the attention on specific aspects of smart cities, or compare them to other different city categories rather than capturing an overall picture of the smart city research. Moreover, they generally conduct bibliometric analyses that are sourced from a limited number of publications and databases in which grey literature is not indexed (Hutton, 2009). Therefore, some relevant source documents may have been missed.

The bibliometric study reported in this paper aims to overcome the limitations of existing bibliometric analyses into smart cities by:

- focusing attention only on the overall intellectual structure of this knowledge domain;

- expanding the number of databases used to source documents ${ }^{3}$;

- including both academic publications and gray literature.

This bibliometric study is carried out using 1,067 source documents identified with a keyword search and combining the analysis of the citations between them, together with citation and publication counts, which are the two most basic bibliometric measures (Tijssen and van Leeuwen, 2003; Martin and Daim, 2008). These documents represent all the smart city literature published in English language between 1992 and 2012. More specifically, that English language literature containing the term 'smart city' or the term 'smart cities', in the title, abstract, keyword list or body of the text, and stored in the following scholarly databases": Google Scholar; ISI Web of Science; IEEE Xplore; Scopus; SpringerLink; Engineering Village; ScienceDirect; and Taylor and Francis Online ${ }^{5}$.

The use of multiple databases makes it possible to conduct a comprehensive interdisciplinary search and broaden the field of investigation, avoiding the risk of not capturing the full extent of research on smart cities. However, it is important to note that this choice is particularly challenging and time consuming because the initial number of publications identified with the keyword search is 9,799. To extract the list of source documents, each publication is included in a single dataset and checked to correct typographical errors in the titles, authors' names or publication dates. Repeated documents that have been found in more than one database are then eliminated. Finally, the title, abstract, keyword list and body of the text of each remaining publication is manually examined to verify the effective presence of the keyword. Documents in which this search has shown to be negative are eliminated.

After completing the search phase, the source documents are cataloged considering their type: abstracts, editorials, journal articles, books, book chapters, conference papers $^{6}$, and grey literature ${ }^{7}$ (Figure 1 ). The last category includes the documents generally defined as grey and"represents a substantial part of the scientific production", especially in recent years (Schopfel and Farace, 2010). According to the most common definition, grey literature represents the literature that is "produced on all levels of government, academics, business and industry in print and electronic formats, but [...] not controlled by commercial publishers, i.e., where publishing is not the 
primary activity of the producing body" (Schopfel, 2010).

All source documents are then linked to authors by their full names and the organizations they represent. Details about organizations are found by searching their official websites, the source documents and the databases used for the keyword search. In this study, the most recent affiliation is attributed to each author. During this activity, data on both the type and location of each organization is also collected (Figure 2). Based on types, four main categories are identified: 1) research and education: universities, academies, and colleges; 2) research and business: private companies operating in the ICT sector which are involved in research and consultancy activities or in the distribution of goods and services; 3) research and government: public authorities and their research institutes); 4) other. In case of organizations operating in multiple locations, the main headquarters are considered.

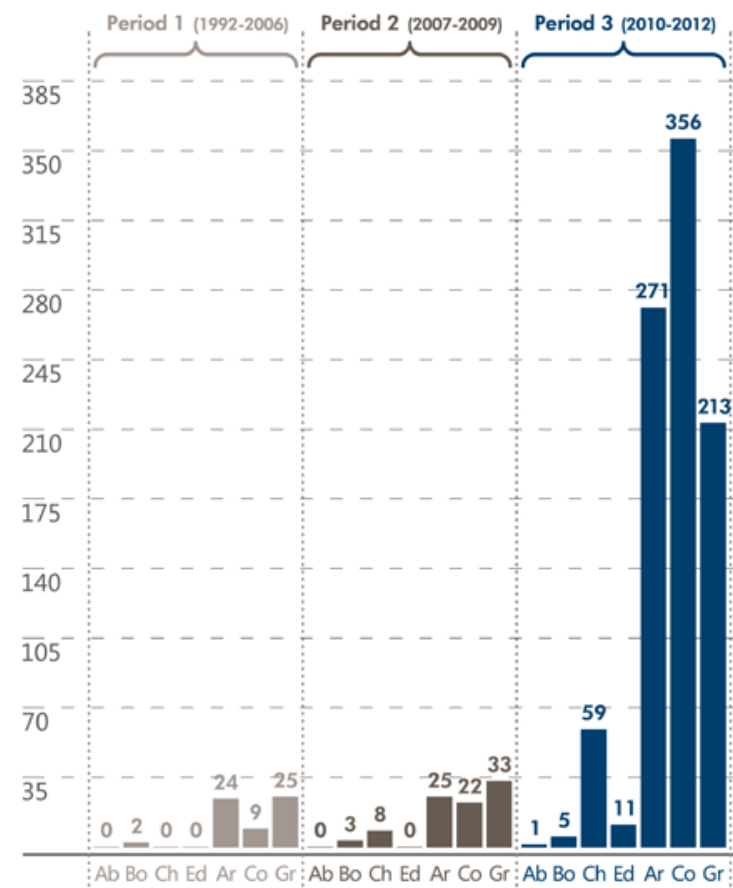

Ab Abstract; Bo Book; Ch Book chapter, Ed Editorial;

Ar Journal article; Co Conference paper; Gr Grey literature

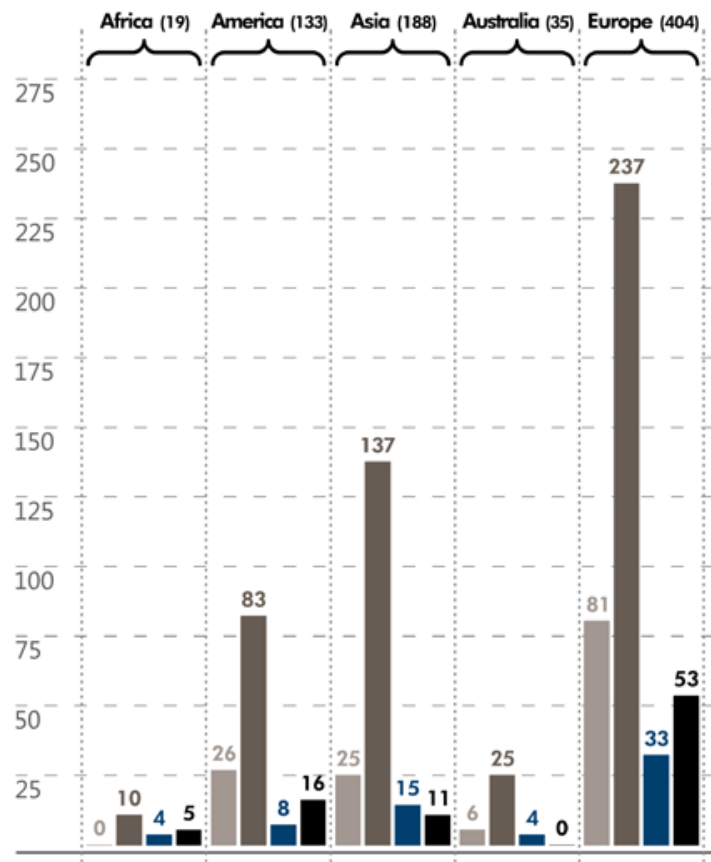

Bu Ed Go Ot: Bu Ed Go Ot: Bu Ed Go Ot: Bu Ed Go Ot: Bu Ed Go Ot

B Research and Business; E Research and Education;

Figure 1. Source documents by type and period of publication

Figure 2. Organizations by type and location

Finally, before starting the analysis, citation data is extracted manually from the list of references included in each source document. In addition, considering that citation data often contain errors, which can lead to significant variations in the results of their analysis (Adam, 2002), all citations have been tested for correctness and completeness, so as to guarantee the highest degree of data reliability. Altogether, a total of 22,137 citations are collected (957 to source documents and 21,180 to nonsource documents), and they are used to build a frequency table showing each cited publication, together with the number of times it has been cited. This makes it possible to determine that the total number of cited references is 17,574 . Only citations to source documents are considered during the analysis. 


\section{The first two decades of smart city research}

\section{A new and fast growing research area}

The analysis shows that smart city research established itself as a new area of scientific enquiry in 2009, and since then, it has been fast growing, arousing strong interest from an expanding scientific community of researchers. This growth is particularly evident when observing the rise in the production of source documents (Figure 3), which has continued to increase over time, together with the number of researchers involved in their development (Figure 4). Initially, this research area was very small, with only 19 source documents published during the first 10 years of research. Over the following eight years, from the beginning of 2002 to the end of 2009, the production has increased slightly. During this period 132 documents have been published, about 17 per year. The period between 2010 and 2012, instead, is characterized by a tremendous growth in the number of publications. More than 900 new source documents are produced in three years, and they represent approximately $86 \%$ of the smart city literature developed during the first two decades of research.

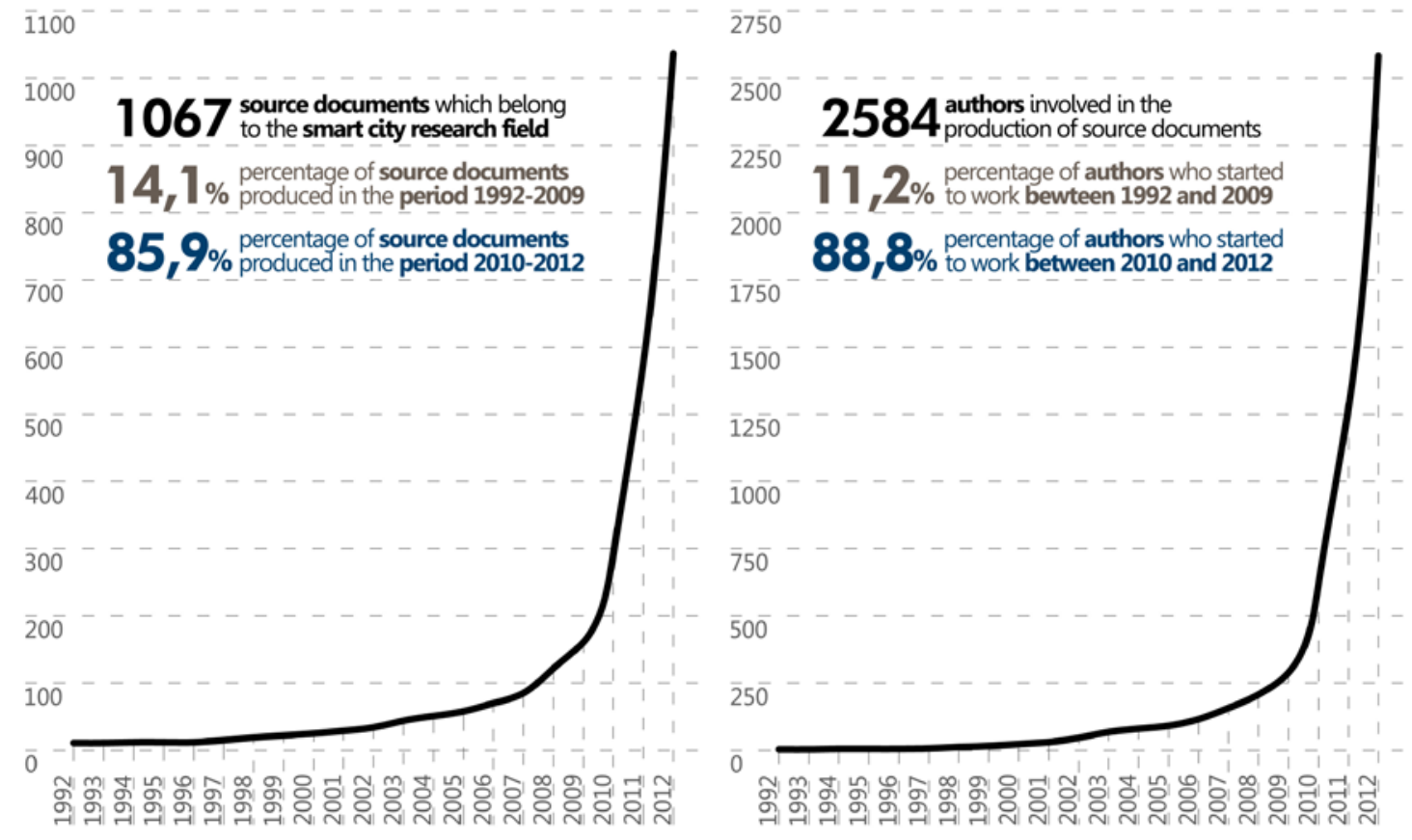

Figure 3. Cumulative growth in the number of source documents

Figure 4. Cumulative growth in the number of authors involved in the production of source documents

\section{Fragmentation of knowledge}

All branches of knowledge are composed of large groups of interconnected publications, and their structure can be represented through the use of complex mapping techniques, allowing the scientific community involved in their production to easily grasp "the big picture" (Moya-Anegon et al., 2004): "a spatial representation of the relationship among [...] individual documents as reflected in some formal, strictly quantifiable properties of scientific literature at a given time" (De Bellis, 2009). Citations are the elements that create the connections between publications. They represent "a type of symbolic currency that signals intellectual influences" and serve as an indicator by which the influence and impact of any scientific document can be assessed 
(Jacobsen et al., 2013). By using citations, researchers can incorporate intellectual work from other research into their own studies (Small 1973; 1978; Garfield, 1970), and collaborate in the construction of the intellectual structure of their field of investigation.

The use of these techniques made it possible to visualize the overall intellectual structure that results from the first 20 years of research in the field of smart cities. The structure is illustrated in Figure 5 , and is represented by a network of undirected and unweighted links in which the 1,067 source documents are nodes and the 957 citations referring to them are the connecting elements. This graph has been obtained using the Fruchterman-Reingold layout algorithm provided by the open-source software Gephi (Fruchterman and Reingold, 1991). Within the graph, the source documents are represented by a circle with a diameter proportional to the number of citations they have received. Therefore, the larger the circle, the greater number of citations. In addition, source documents with at least one citation are shown in blue, whereas those without citations are grey.

By observing the organization of the nodes, it becomes evident that fragmentation and divergence are the main features of this structure, and they result from the absence of connections between the source documents. This means that the impressive growth of available scientific literature observed in the last three years of the second decade goes hand in hand with the lack of cohesion between the researchers involved in their production. As a result, the intellectual structure of the smart city research area is divided into a multitude of unconnected publications. The central core of the network, indeed, is compact and well-articulated thanks to the presence of citations, which indicate an active exchange of knowledge between researchers. However, moving towards the outer perimeter, the organization of the network changes completely. Source documents are disconnected or combined in groups that are small in number and detached from the main core.

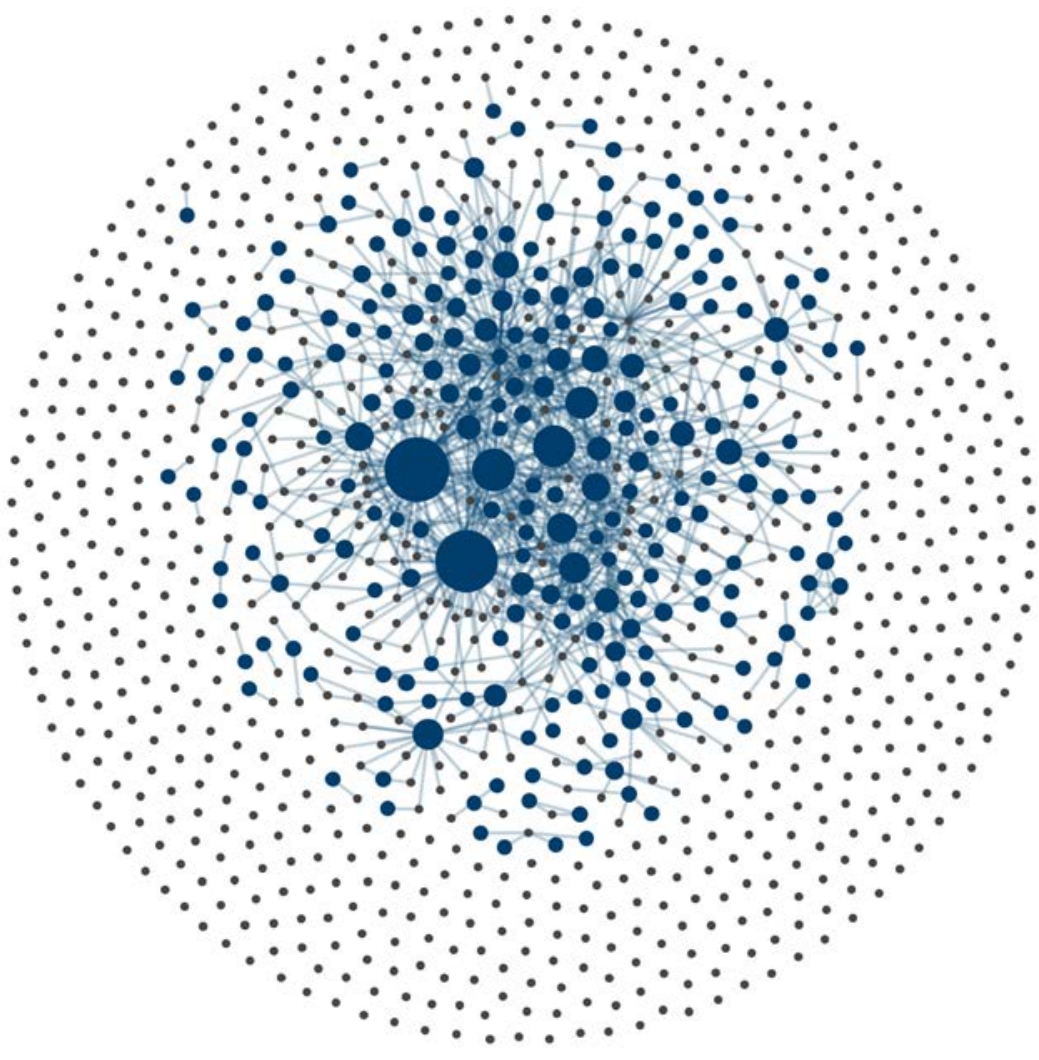

Figure 5. Knowledge structure of the smart city research field
NODE TYPE 1

inot-ciled source do

NODE TYPE 2

INTELLECTUAL EXCHANGE 


\section{The divergent roots of smart cities}

Divergence, lack of cohesion, and limited intellectual exchange among researchers become even more evident when trying to find out a commonly accepted interpretation of smart cities, which is missing. This absence is highlighted in various source documents, such as those produced by Alkandari et al. (2012), Chourabi et al. (2012), Hollands (2008), and Paskaleva (2011). Many definitions of the smart city are provided in scholarly literature and they overlap one another, making it difficult to obtain a common understanding and agreement as to what it means. To illustrate this trend, some of these definitions have been extracted from the source documents and reported in Table 1.

\begin{tabular}{|c|c|}
\hline SOURCE DOCUMENT & DEFINITION \\
\hline Hall et al., 2000 & $\begin{array}{l}\text { "[The smart city is] the urban center of the future, made safe, secure } \\
\text { environmentally green, and efficient because all structures - whether for power, } \\
\text { water, transportation, etc. are designed, constructed, and maintained making use of } \\
\text { advanced, integrated materials, sensors, electronics, and networks which are } \\
\text { interfaced with computerized systems comprised of databases, tracking, and } \\
\text { decision-making algorithms" }\end{array}$ \\
\hline Odendaal, 2003 & $\begin{array}{l}\text { "A smart city }[\ldots] \text { is one that capitalizes on the opportunities presented by } \\
\text { Information and Communication Technology (ICT) in promoting its prosperity and } \\
\text { influence" }\end{array}$ \\
\hline Partridge, 2004 & $\begin{array}{l}\text { "A smart city is [a city that] actively embraces new technologies [seeking] to be a } \\
\text { more open society where technology makes easier for people to have their say, } \\
\text { gain access to services and to stay in touch with what is happening around them, } \\
\text { simply and cheaply" }\end{array}$ \\
\hline Giffinger et al., 2007 & $\begin{array}{l}\text { "A Smart City is a city well performing in a forward-looking way in [...] six } \\
\text { characteristics [...], built on the "smart' combination of endowments and activities of } \\
\text { self-decisive, independent and aware citizens" }\end{array}$ \\
\hline Caragliu et al., 2009 & $\begin{array}{l}\text { "The concept of the 'smart city' has recently been introduced as a strategic device } \\
\text { to encompass modern urban production factors in a common framework and, in } \\
\text { particular, to highlight the importance of Information and Communication } \\
\text { Technologies (ICTS) in the last } 20 \text { years for enhancing the competitive profile of a } \\
\text { city" }\end{array}$ \\
\hline Paskaleva, 2009 & $\begin{array}{l}\text { "In the context of the present study, the smart city is defined as one that takes } \\
\text { advantages of the opportunities offered by ICT in increasing local prosperity and } \\
\text { competitiveness - an approach that implies integrated urban development involving } \\
\text { multi-actor, multi-sector and multi-level perspectives" }\end{array}$ \\
\hline Belissent et al., 2010 & $\begin{array}{l}\text { "Forrester defines the smart city as [...] a "city" that uses information and } \\
\text { communications technologies to make the critical infrastructure components and } \\
\text { services of a city - administration, education, healthcare, public safety, real estate, } \\
\text { transportation, and utilities - more aware, interactive, and efficient" }\end{array}$ \\
\hline Hernández-Muñoz et al., 2011 & $\begin{array}{l}\text { "Smart Cities can represent an extraordinary rich ecosystem to promote the } \\
\text { generation of massive deployments of city-scale applications and services for a } \\
\text { large number of activity sectors" }\end{array}$ \\
\hline Alkandari et al., 2012 & $\begin{array}{l}\text { "A smart city is one that uses a smart system characterized by the interaction } \\
\text { between infrastructure, capital, behaviours and cultures, achieved through their } \\
\text { integration" }\end{array}$ \\
\hline Lazaroiu and Roscia, 2012 & $\begin{array}{l}\text { "A new city model, called "the smart city", which represents a community of } \\
\text { average technology size, interconnected and sustainable, comfortable, attractive } \\
\text { and secure" }\end{array}$ \\
\hline Schaffers et al., 2012 & $\begin{array}{l}\text { "The smart city concept is multi-dimensional. It is a future scenario (what to } \\
\text { achieve), even more it is an urban development strategy (how to achieve it). It } \\
\text { focuses on how (Internet-related) technologies enhance the lives of citizens [...] } \\
\text { The smart city is about how people are empowered, through using technology, for } \\
\text { contributing to urban change and realizing their ambitions. The smart city provides } \\
\text { the conditions and resources for change. In this sense, the smart city is an urban } \\
\text { laboratory, an urban innovation ecosystem, a living lab, an agent of change" }\end{array}$ \\
\hline
\end{tabular}

Table 1. Some definitions of smart cities extracted from the source documents

In this confused scenario, two dominant interpretative models emerge from the analysis of the relationship between the 10 most cited source documents (Figure 6) and their content. These publications can be split into two different groups, and their division depends on the interpretation of smart cities they support. The first group of 
publications is connected by a single network of citations, which provide evidence of an active exchange of knowledge between researchers, and promotes an interpretation which can be defined as holistic. In this case, smart cities are described as the result of the balanced combination of human, social, cultural, economic, environmental, and technological aspects, which stand alongside one another. The second group of publications, instead, is composed of source documents which are disconnected, and provide a techno-centric interpretation of smart cities.
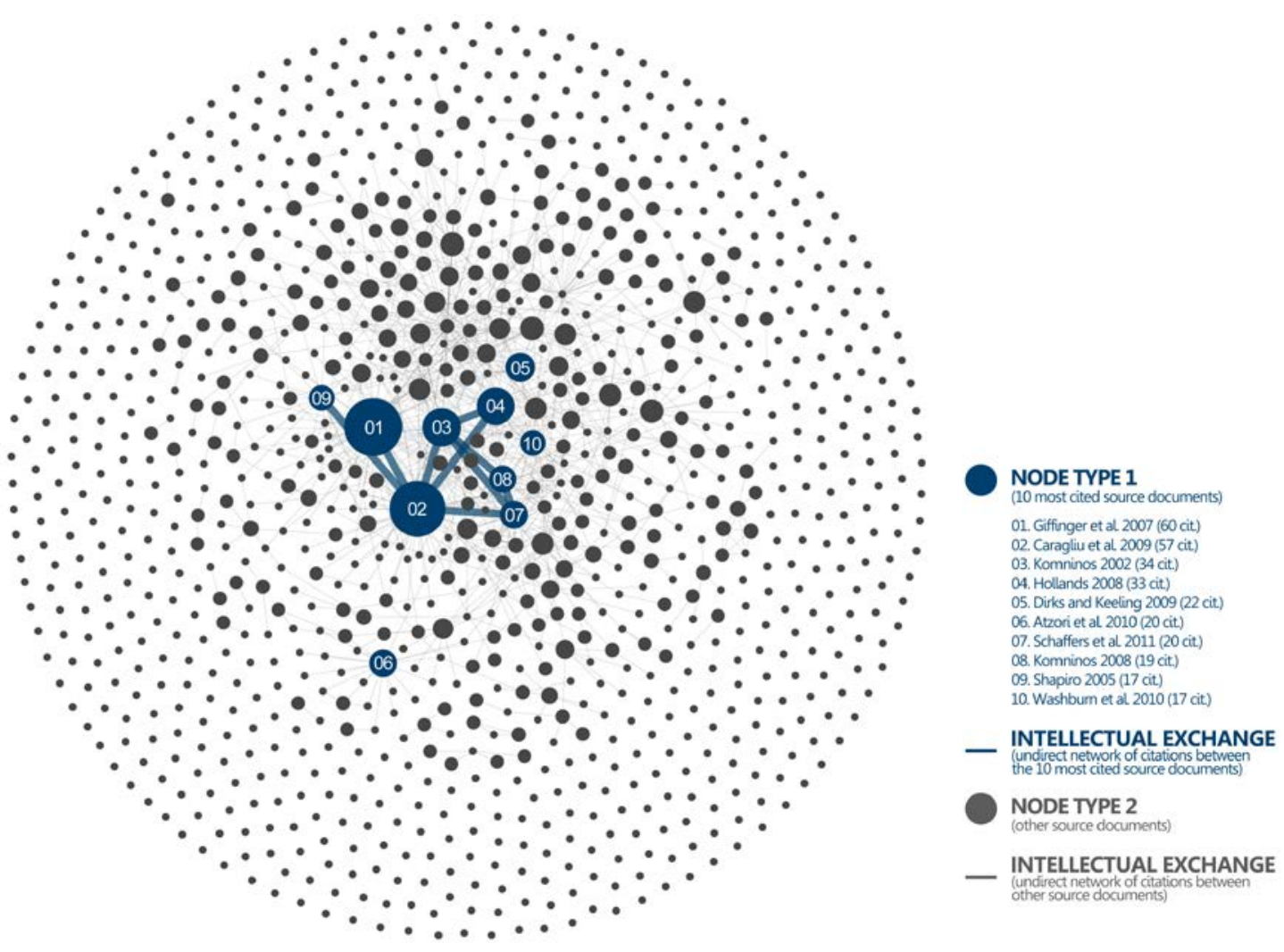

Figure 6. Relationship between the 10 most cited source documents included in the smart city knowledge structure

The holistic perspective is supported in the research report published by Giffinger et al. (2007), which is the most influent source document published between 1992 and 2012. This publication moves the smart city concept away from an excessively technological perspective, and offers a human-centric reading of the subject. Here smart cities are not simply places with a high availability of ICTs, but urban areas "well performing in a forward-looking way in [...] six characteristics [economy, people, governance, mobility, environment, and living], built on the 'smart' combination of endowments and activities of self-decisive, independent and aware citizens". The conference paper by Caragliu et al. (2009) makes a significant contribution to this vision, and the authors take this further with the journal article Caragliu et al. (2011). According to their vision: "a city [is] smart when investments in human and social capital and traditional (transport) and modern (ICT) communication infrastructure fuel sustainable economic growth and a high quality of life, with a wise management of natural resources, through participatory governance".

This holistic interpretation is also supported by Schaffers et al. (2011), but more importantly, responds to the request made by Hollands (2008) for a more progressive view of the smart city concept, which "must seriously start with people and the human capital side of the equation, rather than blindly believing that IT itself can automatically 
transform and improve cities". This is a point already stressed in research by Komninos (2006, quoted in Hollands, 2008), where the smart city concept is merged with the intelligent city concept. The latter defined as: "territories with high capacity for learning and innovation, which is built-in to the creativity of their population, their institutions of knowledge creation, and their digital infrastructure for communication and knowledge management". According to Komninos, therefore, a smart city is an urban area in which the technological, human, social and cultural capital of a community offers the means to generate new knowledge of urban problems and an increased capability to face them (Komninos, 2002; 2008).

In direct contrast to this interpretation, the smart city conceived by Dirks and Keeling (2009), both researchers at IBM (International Business Machines Corporation), is an urban environment permeated with ICTs, where all physical infrastructures are interconnected. In this case, the focus is almost exclusively on the singular role of new technologies in developing integrated platforms of city services. This is the same interpretation provided by a group of researchers from Forrester Research: "what makes a [city] smart is the combined use of software systems, server infrastructure, network infrastructure, and client devices - which Forrester calls Smart Computing technologies - to better connect seven critical city infrastructure components and services: city administration, education, healthcare, public safety, real estate, transportation, and utilities" (Washburn et al., 2010). All this is made possible by the continuous and rapid diffusion of electronic devices capable of retrieving and transmitting data, such as smartphones and sensors, which have supported the growth of the Internet of Things (IOT). That web-based service development which is reported by Atzori et al. (2010).

\section{The geography of knowledge production}

The scientific community working in the field of smart cities between 1992 and 2012 is made up of 2,584 researchers, divided among 779 organizations which are located in 434 cities and 69 countries. To assess their productivity and influence, a calculation has been made as to the quantity of source documents produced by each author and the number of citations they have acquired. For publications produced by two or more authors, the unit value of the document and the number of citations it has acquired have been divided by the number of authors involved, so each can be assigned an equal share. In this way, individual researchers have become the basic elements for extending the analysis to the organizations in which they work, as well as the countries and continents where they are located. The process just described is shown in Figure 7.

The results show that smart city research starts in Australia and North America. Subsequently, interest in the subject grows and the production of literature on smart cities has developed in Europe, Asia, and Africa, between 1997 and 2000, and in South America, but not before 2010. Up to 2002, North America maintains the greatest number of authors and the highest number of publications, but this condition changes between 2002 and 2012, a period during which the number of European authors increases from 17 to 1,327 (Table 2). These authors represent more than half of the global scientific community involved in smart city research (51.4\%) between 1992 and 2012. The rest of this community is located in other continents, especially Asia, in which 667 researchers have been identified (25.8\%). If compared with American organizations (16.6\%), Australia (3.9\%), and Africa (1.7\%), this value is certainly much higher.

Europe is also the largest contributor to the growth of smart city research and the region that has influenced most the intellectual structure of this fast-expanding field of scientific enquiry. The majority of source documents are produced by organizations located in Europe (52\%) and they have the greatest overall impact. The situation is 


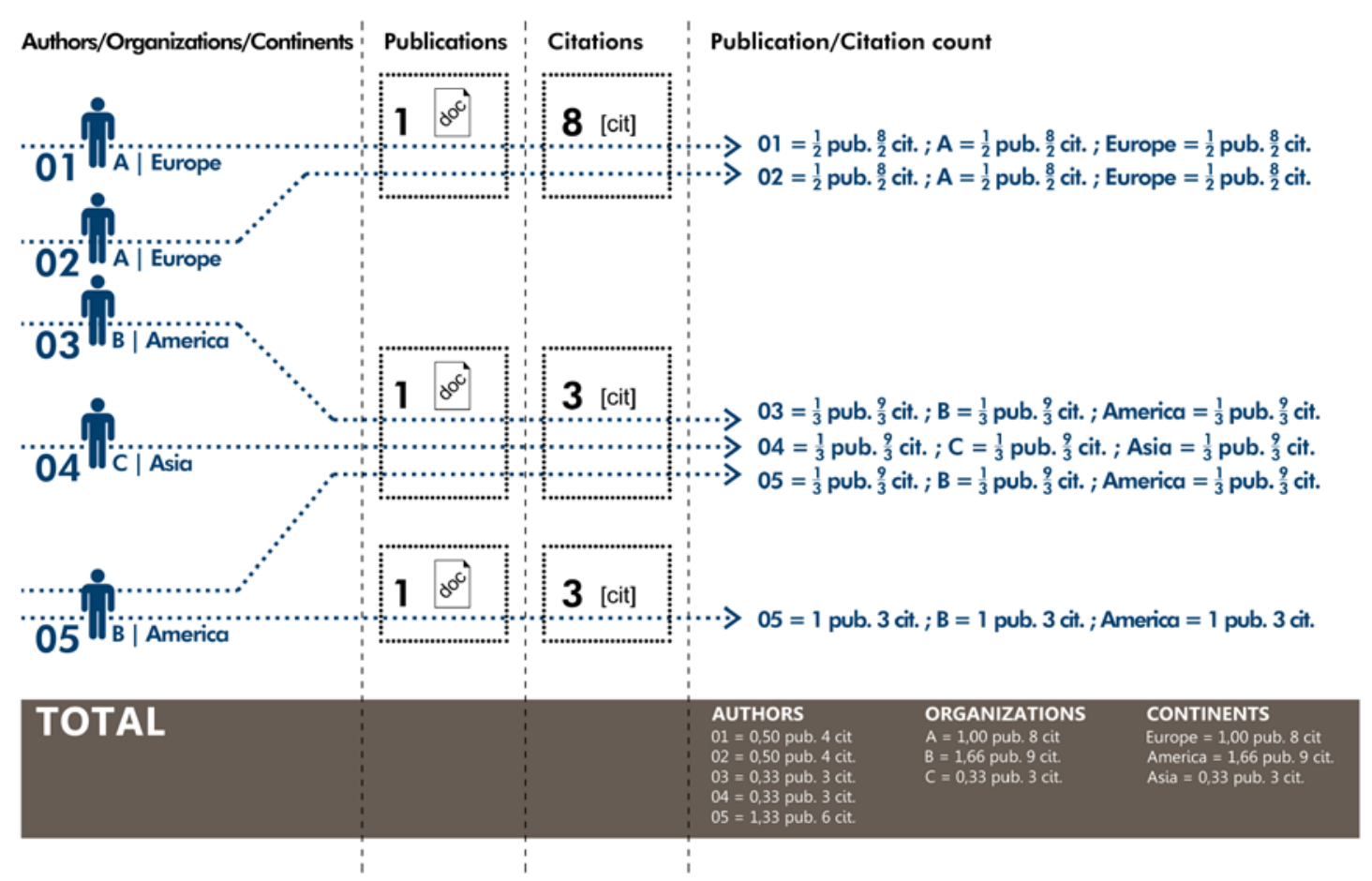

Figure 7. Procedure for estimating productivity and influence of authors, organizations, countries, and continents

\begin{tabular}{|c|c|c|c|c|c|c|}
\hline \multirow[t]{2}{*}{ YEAR } & \multicolumn{6}{|c|}{ NUMBER OF AUTHORS (Annual growth / Cumulative growth) } \\
\hline & Africa & Asia & Australia & Europe & North America & South America \\
\hline 1992 & $0(0)$ & $0(0)$ & $0(0)$ & $0(0)$ & $+3(3)$ & $0(0)$ \\
\hline 1993 & $0(0)$ & $0(0)$ & $0(0)$ & $0(0)$ & $0(3)$ & $0(0)$ \\
\hline 1994 & $0(0)$ & $0(0)$ & $+2(2)$ & $0(0)$ & $0(3)$ & $0(0)$ \\
\hline 1995 & $0(0)$ & $0(0)$ & $0(2)$ & $0(0)$ & $0(3)$ & $0(0)$ \\
\hline 1996 & $0(0)$ & $0(0)$ & $0(2)$ & $0(0)$ & $0(3)$ & $0(0)$ \\
\hline 1997 & $0(0)$ & $0(0)$ & $0(2)$ & $+3(3)$ & $0(3)$ & $0(0)$ \\
\hline 1998 & $0(0)$ & $+1(1)$ & $0(2)$ & $0(3)$ & $+3(6)$ & $0(0)$ \\
\hline 1999 & $0(0)$ & $+1(2)$ & +3 (5) & $0(3)$ & $0(6)$ & $0(0)$ \\
\hline 2000 & $+1(1)$ & $0(2)$ & 0 (5) & $+1(4)$ & $+6(12)$ & $0(0)$ \\
\hline 2001 & $0(1)$ & $0(2)$ & $+1(6)$ & +1 (5) & $+4(16)$ & $0(0)$ \\
\hline 2002 & $0(1)$ & $0(2)$ & $+5(11)$ & +12 (17) & $0(16)$ & $0(0)$ \\
\hline 2003 & $+1(2)$ & $0(2)$ & $+2(13)$ & $+14(31)$ & +3 (19) & $0(0)$ \\
\hline 2004 & $+2(4)$ & $+2(4)$ & $+3(16)$ & $+1(32)$ & $+6(25)$ & $0(0)$ \\
\hline 2005 & $+3(7)$ & $0(4)$ & $+5(21)$ & $0(32)$ & $+2(27)$ & $0(0)$ \\
\hline 2006 & $+1(8)$ & $+3(7)$ & $0(21)$ & +19 (51) & $+2(29)$ & $0(0)$ \\
\hline 2007 & $+1(9)$ & +16 (23) & $+6(27)$ & $+9(60)$ & +9 (38) & $0(0)$ \\
\hline 2008 & +7 (16) & $+12(35)$ & $+5(32)$ & +20(80) & $+6(44)$ & $0(0)$ \\
\hline 2009 & +1 (17) & $+25(60)$ & $+2(34)$ & +34 (114) & +21 (65) & $0(0)$ \\
\hline 2010 & $0(17)$ & +81 (141) & +11 (45) & $+148(262)$ & +84 (149) & $+5(5)$ \\
\hline 2011 & +9 (26) & $+152(293)$ & +24(69) & $+351(613)$ & +119 (268) & 0 (5) \\
\hline 2012 & +19 (45) & $+374(667)$ & $+31(100)$ & $+714(1327)$ & +162(430) & +10 (15) \\
\hline
\end{tabular}

Table 2. Growth in the number of authors involved in the production of source documents by continent

also positive in North America, where researchers have published $16.6 \%$ of the source documents, accounting for $24.4 \%$ of the total citations. In the case of Asia, indeed, the relationship between production and influence is negative. Here the overall impact is much smaller (10.3\%), despite a greater share of source documents $(23.3 \%)$. This data 
is included in Figure 8.

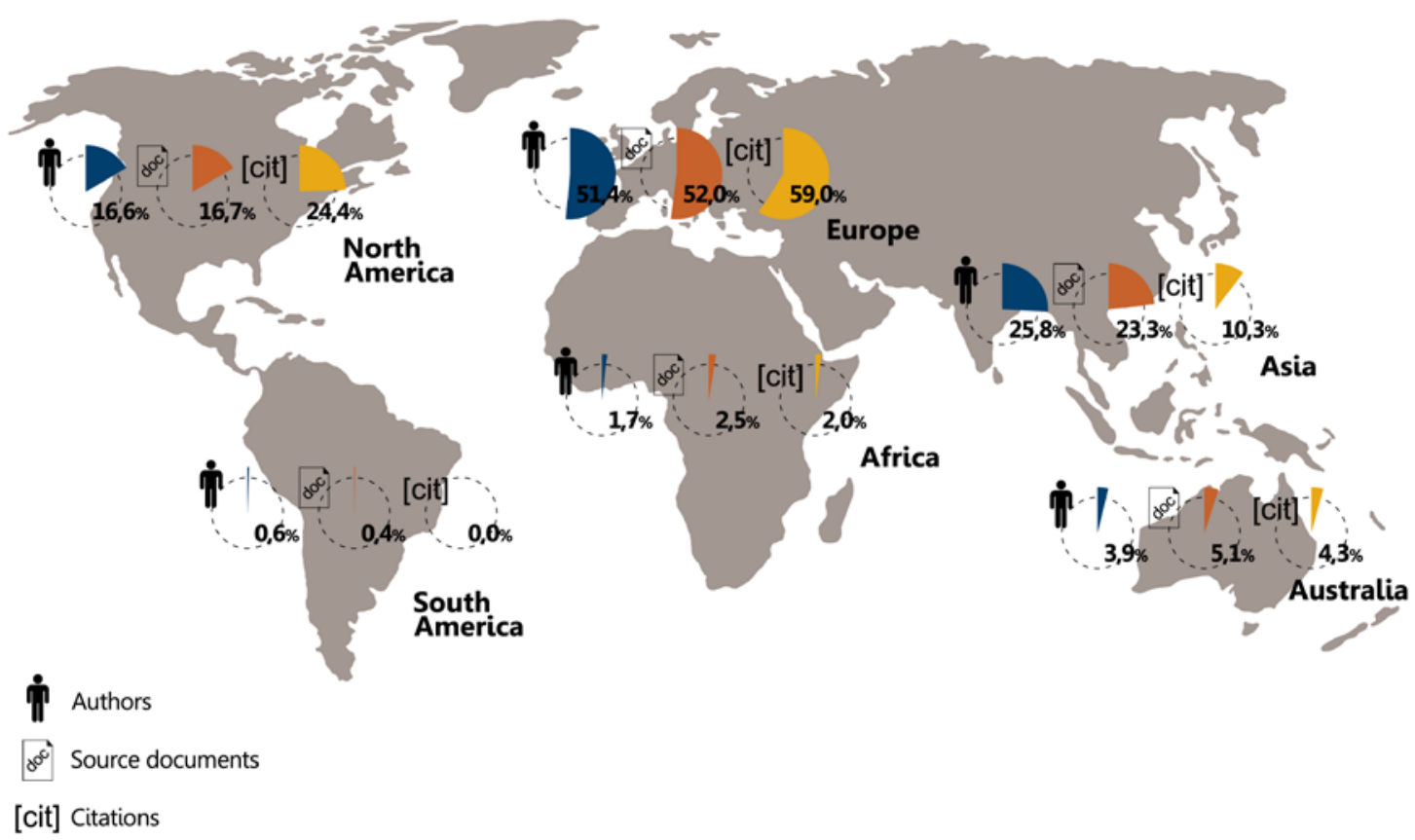

Figure 8. Percentage of authors, source documents, and citations by continents

Therefore, Europe and North America have become the main knowledge hubs in the field of smart cities. However, they are characterized by three important differences. A cross-cutting reading of the data reported in Table 3, Table 4, and Table 5 makes it possible to analyze the first one. This data shows that European research on smart cities is conducted mainly in universities, which have the greatest impact and highest productivity. It also shows that most of the European authors are from academics and these account for not only $68 \%$ of the European source documents, but also about $72 \%$ of the citations. Conversely, in North America, the highest productivity is linked to both universities and businesses operating in the ICT sector. However, between these two knowledge producers, the latter has certainly a dominant role, especially IBM and Forrester Research. Altogether, these two companies account for about $50 \%$ of the total citations acquired by US organizations during the period 19922012 , and nearly $70 \%$ of the source documents they have produced. Moreover, with 100 researchers working in the field of smart cities, at the end of 2012, IBM was the world's leading organization in terms of authors, productivity, and influence over the development of this research area.

The remaining two differences, instead, regard: 1) the divergent interpretation of the smart city provided by each knowledge hub; 2) the approach used by its researchers to produce and diffuse the literature on smart cities which describe these interpretations. Both differences can be observed by comparing the most cited source documents produced respectively in Europe (Table 6) and North America (Table 7). The European knowledge hub supports the holistic interpretative model of smart cities. This model stems mainly from grey literature (Caragliu et al., 2009; Giffinger et al., 2007), but over the years, it has been progressively consolidated within the peerreviewed literature of the academic world (Komninos, 2002; 2008; Hollands, 2008; Schaffers et al., 2011; Paskaleva, 2009). On the contrary, North American businesses support the techno-centric interpretation, whose foundations are built primarily by publications passing through the more informal channels of grey literature (Dirks and 
Keeling, 2009; Washburn et al., 2010; Moss Kanter and Litow, 2009; Dirks et al., 2009; 2010; Belissent et al., 2010; Hall et al., 2000).

Finally, African and Asian organizations do not seem to have significantly influenced the development of smart city research. This situation reflects the production volume of the few researchers working in the African continent. However, this is not the case in Asia, because some of the most productive organizations are based in India and Japan. For example, Hitachi and the Tata Group, which have produced almost 4\% of the total source documents, thanks to the work of 92 researchers. These are very high numbers, matched only by IBM. However, the American company has been able to gain a completely different influence, with $9 \%$ of the total citations as against the $0.8 \%$ attributed to the two Asian companies.

\begin{tabular}{l|c|ll|ccc}
\hline ORGANIZATION & TYPE & LOCATION & & \multicolumn{2}{|c}{ \% ON TOTAL } & \\
& & Country & Continent & Cit. & Doc. & Auth. \\
\hline IBM & B & United States & North America & 8.9 & 3.3 & 3.9 \\
Aristotle University of Thessaloniki & E & Greece & Europe & 7.5 & 1.0 & 0.4 \\
Vienna University of Technology & E & Austria & Europe & 5.0 & 0.7 & 0.7 \\
Newcastle University & E & United Kingdom & Europe & 3.4 & 0.1 & 0.1 \\
Forrester Research & B & United States & North America & 2.9 & 0.3 & 0.3 \\
SAP Research & B & Germany & Europe & 2.7 & 0.8 & 0.3 \\
University of Chicago & E & United States & North America & 2.6 & 0.2 & 0.1 \\
Queensland University of Technology & E & Australia & Australia & 2.6 & 1.0 & 0.4 \\
Politecnico di Milano & E & Italy & Europe & 2.4 & 1.3 & 1.0 \\
Vrije University Amsterdam & E & The Netherlands & Europe & 2.2 & 0.4 & 0.2 \\
\hline
\end{tabular}

Table 4. The 10 most cited organizations in the world. B: Research and Business; E: Research and Education; G: Research and Government; O: Other

\begin{tabular}{l|c|ll|llc}
\hline ORGANIZATION & TYPE & LOCATION & & \multicolumn{3}{|c}{ \% ON TOTAL } \\
& & Country & Continent & Cit. & Doc. & Auth. \\
\hline IBM & B & United States & North America & 8.9 & 3.3 & 3.9 \\
Hitachi & B & Japan & Asia & 0.5 & 2.2 & 2.9 \\
Politecnico di Milano & E & Italy & Europe & 2.4 & 1.3 & 1.0 \\
Aristotle University of Thessaloniki & E & Greece & Europe & 7.5 & 1.0 & 0.4 \\
Queensland University of Technology & E & Australia & Australia & 2.6 & 1.0 & 0.4 \\
SAP Research & B & Germany & Europe & 2.7 & 0.8 & 0.3 \\
Edinburgh Napier University & E & United States & Europe & 0.8 & 0.8 & 0.3 \\
European Union & G & Belgium & Europe & 1.0 & 0.8 & 0.7 \\
Tata Group & B & India & Asia & 0.3 & 0.7 & 0.7 \\
Vienna University of Technology & E & Austria & Europe & 5.0 & 0.7 & 0.7 \\
\hline
\end{tabular}

Table 5. The 10 most productive organizations in the world. B: Research and Business; E: Research and Education; G: Research and Government; O: Other

\begin{tabular}{|c|c|c|c|}
\hline SOURCE DOCUMENTS & ORGANIZATIONS & TYPE & CITATIONS \\
\hline Giffinger et al., 2007 & $\begin{array}{l}\text { Delft University of Technology (E); University of } \\
\text { Ljubljana (E); Vienna University of Technology (E) }\end{array}$ & $\mathrm{Gr}$ & 60 \\
\hline Caragliu et al., 2009 & $\begin{array}{l}\text { Politecnico di Milano (E); University of Milan (E); Vrije } \\
\text { University Amsterdam (E) }\end{array}$ & $\mathrm{Gr}$ & 57 \\
\hline Komninos, 2002 & Aristotle University of Thessaloniki (E) & Bo & 34 \\
\hline Hollands, 2008 & Newcastle University (E) & $\mathrm{Ar}$ & 33 \\
\hline Atzori et al., 2010 & $\begin{array}{l}\text { Mediterranea University of Reggio Calabria }(E) \text {; } \\
\text { University of Catania }(E) \text {; University of Cagliari }(E)\end{array}$ & $\mathrm{Ar}$ & 20 \\
\hline Schaffers et al., 2011 & $\begin{array}{l}\text { INRIA (G); Aristotle University of Thessaloniki }(E) \text {; } \\
\text { ESoCE Net }(O) \text {; Alfamicro }(B) \text {; Lulea University of } \\
\text { Technology }(E)\end{array}$ & $\mathrm{Ch}$ & 20 \\
\hline Komninos, 2008 & Aristotle University of Thessaloniki (E) & Bo & 19 \\
\hline Paskaleva, 2009 & University of Manchester (E) & $\mathrm{Ar}$ & 15 \\
\hline
\end{tabular}




\begin{tabular}{l|l|c|c}
\hline The Climate Group, 2008 & The Climate Group (O) & Gr & 14 \\
$\begin{array}{l}\text { Karnouskos and Nass de } \\
\text { Holanda, 2009 }\end{array}$ & Co & 12 \\
$\begin{array}{l}\text { Hernández-Muñoz et al., 2011 } \\
\text { SAPearch (B) }\end{array}$ & $\begin{array}{l}\text { Alexandra Institute (B); University of Cantabria (E); } \\
\text { Polytechnic University of Madrid (E); Telefonica I+D } \\
\text { (B); Lulea University of Technology (E) }\end{array}$ & Ch & 12 \\
\hline
\end{tabular}

Table 6. The 10 most cited source documents produced by European organizations. Ab: Abstract; Ed: Editorial; Ar: Journal article; Bo: Book; Ch: Book chapter; Co: Conference paper; Gr: Grey literature; B: Research and Business; E: Research and Education; G: Research and Government; O: Other

\begin{tabular}{l|l|c|c}
\hline SOURCE DOCUMENT & ORGANIZATIONS & TYPE & CITATIONS \\
\hline Dirks and Keeling, 2009 & IBM (B) & $\mathrm{Gr}$ & 22 \\
Shapiro, 2005 & University of Chicago (E) & $\mathrm{Gr}$ & 17 \\
Washburn et al., 2010 & Forrester Research (B) & $\mathrm{Gr}$ & 17 \\
Naphade et al., 2011 & IBM (B) & $\mathrm{Ar}$ & 13 \\
Coe et al., 2001 & University of Ottawa (E) & $\mathrm{Ar}$ & 12 \\
Moss Kanter and Litow, 2009 & Harvard University (E); IBM (B) & $\mathrm{Gr}$ & 12 \\
Dirks et al., 2009 & IBM (B) & $\mathrm{Gr}$ & 11 \\
Dirks et al., 2010 & IBM (B) & 11 \\
Belissent et al., 2010 & Forrester Research (B) & $\mathrm{Gr}$ & 10 \\
Hall et al., 2000 & Brookhaven National Laboratory (G) & $\mathrm{Gr}$ & 8 \\
\hline
\end{tabular}

Table 7. The 10 most cited source documents produced by North American organizations. Ab: Abstract; Ed: Editorial; Ar: Journal article; Bo: Book; Ch: Book chapter; Co: Conference paper; Gr: Grey literature; B: Research and Business; E: Research and Education; G: Research and Government; O: Other

\section{A new, promising, but divided research area}

This bibliometric analysis provides an overall picture of the first two decades of research on smart cities. The results show the amount of literature shaping this new research area and its intellectual structure has grown continuously during the period under investigation, especially since 2009. However, the limited intellectual exchange and lack of cohesion characterizing this structure have resulted in a situation whereby smart city researchers illustrate a tendency to follow personal trajectories in isolation from one another. As a result, the publications that they produce remain separated from one another as objects of knowledge divided along lines of enquiry that do not converge. In this scenario, the growth of smart city research follows two main development paths. The first one is based on peer-reviewed publications produced by European universities and those developing a holistic interpretation of smart cities. The second path, on the contrary, stands on the grey literature produced by the North American business world and its consultancy firms, which are promoting a technocentric understanding of this subject.

This big picture on smart city research only relates to developments taking place between 1992 and 2012, but it nevertheless does serve to highlight the source of that division which still preoccupies many of the ongoing enquiries. For if we review the literature produced after 2012, indeed, the situation does not seem to change. This is because, while leading academics in the field continue to characterize smart cities as a new and promising topic of research, "there is still not a clear and consistent understanding of [this] concept" (Chourabi et al., 2012) and the work of defining and conceptualizing it is still in progress (Albino et al., 2015; Fernandez-Anez, 2016; Cocchia and Damieri, 2016; Ojo et al., 2016). Consequently, rather than overcoming the fragmentation that has been generated over the first 20 years, smart city research remains divided along the same lines of enquiry, and researchers are still left searching 
for definitions which are capable of bridging them. Some examples are Kitchin (2014), Townsend (2013), Greco and Cresta (2015), Urzaiz et al. (2014) and Christopoulou et al. (2014).

The bibliometric analysis of the smart city research reported on in this paper shows the locus of the academic exchange currently taking place on the defining features of smart cities, as a point of intersection between two development paths. Two competing development paths, which are structurally divided in terms of both the form and content that each advances to define the smart city as an object of scientific enquiry.

On one hand, there is the development path promoting the techno-centric vision of smart cities. This vision proposes the smart city as an engine that fuels ICT companies and which is expected to exceed hundreds of billions of dollars by 2020 (Zanella et al., 2014). Driven by the desire to exploit this new and promising market, because it can "provide [them] with alternative growth initiatives, particularly in a recession environment" (Paroutis et al., 2014), large companies such as Cisco Systems (Amato et al., 2012), ABB (2013) and Fujitsu (Tamai, 2014) have decided to follow IBM, and deploy ICTs as vehicles of urban innovation that drive smart city development.

This corporate smart city model is criticized for the reason it fails to account for the social and cultural challenges that smart city developments pose in anything but technological terms. For in the corporate model, smart cities are assumed to arise from: 1) the concentration and interconnection of technological solutions able to capture and manage large amounts of data; 2) computing models and algorithms which use such data to cure the inefficiencies that cities exhibit (Townsend, 2013; Soderstrom et al., 2014; Hollands, 2015, 2016; McNeill, 2016). The ineffectiveness of this model is empirically demonstrated by Shin $(2007 ; 2009 ; 2010)$, who highlights the weaknesses of the corporate and techno-centric smart cities developed by South Korea. Some examples of these smart cities are reported on by Yigitcanlar (2016), Townsend (2013), Anttiroiko (2013), Yigitcanlar and Lee (2014) and Shwayri (2013). They include the limitations of smart city development in Busan, Seoul, and Songdo International Business District, which is located along the waterfront of Incheon.

On the other hand, over the last four years, a holistic interpretation of smart cities has emerged within the academic world and acquired support from the scientific community. This interpretation is based on a progressive and human-centric perspective of ICT-driven urban innovation and development, and the balanced combination of human, social, cultural, environmental, economic and technological aspects (Hemment and Townsend, 2013; Townsend, 2013; Angelidou, 2014; Komninos, 2014; Hollands, 2015; 2016; Christopoulou et al., 2014; Concilio and Rizzo, 2016). However, as reported by Lee et al. (2014), the research supporting this vision of smart cities still "remains at a preliminary stage", because the knowledge gap between theory and practice has not yet been filled. "What elements go into making up a smart city" (Hollands, 2015) and how to both design and implement strategies capable of building smart cities continue to be relevant subject-matters of investigation (Lazaroiu and Roscia, 2012; Zygiaris, 2013; Komninos, 2014; Bolici and Mora, 2015). But unfortunately, there is currently little agreement across the scientific community on how to conduct research capable of generating the evidence needed to bridge this gap (Deakin, 2014).

As Lee et al. (2014) also go on to state: "discussions in academic literature of relevant [theories] or frameworks are few [and the] analysis lags behind the actual practice of how different cities [...] are moving towards transforming themselves into a smart [...] city. Even though actual practice often remains fragmented, real world implementation still generally outstrips any discussion in academic literature capable of generalization". As a result, the knowledge necessary to understand the process of building effective smart cities in the real world has not yet been produced, and neither 
are the tools for supporting the actors involved in this activity.

\section{Conclusion}

The results of this analysis indicate that the main reason for the confusion around the scientific status of smart city research rests with the:

- lack of intellectual exchange between those conducting research in the field of smart cities;

- tendency smart city researchers have to be subjective and follow personal trajectories in isolation from one another;

- divisions that smart city research opens up in the scientific community;

- struggle the community has to find any common currency between the knowledge smart city research produces;

- disagreement the research generates as to the ways of conceptualizing and defining the smart city, which emerges as one of the main terms of reference for ICT-related urban innovation.

This situation leaves smart city research fragmented and divided along two main development paths and in a position whereby the future development of this new, promising, but divided area of research is put at risk. For while the bibliometric analysis indicates that smart cities are emerging as a fast-growing topic of scientific enquiry, much of the knowledge which is generated about them is singularly technological in nature. In that sense, lacking the social intelligence, cultural artifacts, and environmental attributes which are needed for the ICT-related urban innovation such research champions to be smart in securing the physical infrastructure requirements of cities.

To address the challenge which is posed by this situation, the intellectual exchange between the members of the scientific community researching smart cities need to increase markedly. Rather than running the risk of becoming entrenched along the lines of division reported on in this paper, researchers should instead begin to search out the grounds to transcend them by 'acting in concert'. What is more, smart city researchers need to achieve this aim by integrating their respective fields of specialization using a model or mode of scientific enquiry which not only manages to bridge the structural division that is highlighted, but does it in a form whose content adds up to more than the 'sum-of-the-parts'. This will support the construction of the collaborative environment which is necessary to generate a possible agreement concerning the way of thinking about, conceptualizing, and defining the smart city.

\section{Notes}

1. The keyword search has been performed on April 2016 using the search query: "smart city" OR "smart cities" (Baseline 1992).

2. This growth is documented and discussed in other recent studies produced by Wolfram (2012) and D'Auria et al. (2014).

3. As suggested by De Bellis (2009) and Small and Griffith (1974), any field of research can be envisioned as a mosaic or puzzle of individual units (scientific documents) clustered together by way of subject-related repositories (journals) and produced through the research activities performed by a community of scholars (authors). These publications represent the output of research conducted into a specific field of study and raw data for performing bibliometric analyses. Therefore, they are defined as source documents (Small and Crane, 1979; Shiau and Dwivedi, 2013.

4. No searches are done to retrieve all available literature on smart cities. The keyword search is limited to English language documents. 
5. "Many new categories of cities have entered the policy discourse: sustainable cities; green cities; digital cities; smart cities; intelligent cities; information cities; knowledge cities; resilient cities; eco cities; low carbon cities; liveable cities; and even combinations, such as low carbon eco cities and ubiquitous eco cities" (de Jong et al., 2015). However, within the literature on urban development and innovation, these categories of cities are used interchangeably, even if they are characterized by conceptual and practical differences (Jong et al., 2015). This generates the terminological confusion described by Hollands (2008) and Deakin and Al Wear (2011). Taking such differences into account and mindful of this study's specific interest in smart cities, a decision was made to set the keyword search so that only documents containing the term 'smart city' in singular or plural form were captured. These are considered to be the core documents for exploring what smart cities mean as knowledge objects. No varying or related terms are therefore considered in this search. This avoids the risk of adversely affecting the bibliometric study by including documents not directly connected to smart cities as a knowledge domain.

6. Considering the definition provided by Schopfel (2010), only conference papers included in repositories controlled by commercial publishers such as Springer, ACM (Association for Computing Machinery), IEEE (Institute of Electrical and Electronics Engineers), and Elsevier are not considered as grey literature.

7. Most of the grey literature is extracted form Google Scholar, which is a database particularly recommended for identifying this kind of publications (Hutton 2009).

\section{References}

ABB, ABB Power and Automation: Solid Foundations for Smart Cities (Zurich: ABB, 2013) <http://new.abb.com/docs/default-source/smart-gridslibrary/abb_smart_grids_white_paper_2013.pdf?sfvrsn=2> Accessed April 5, 2014.

D. Adam, "The Counting House," Nature 415:6873 (2002) 726-729.

V. Albino, U. Berardi, and R.M. Dangelico, "Smart Cities: Definitions, Dimensions, Performance, and Initiatives," Journal of Urban Technology 22:1 (2015) 3-21.

A. Alkandari, M. Alnasheet, and I.F. Alshekhly, "Smart Cities: Survey," Journal of Advanced Computer Science and Technology Research 2:2 (2012) 79-90.

V. Amato, L. Bloomer, A. Holmes, and S. Kondepudi, Using ICT to Deliver Benefits to Cities by Enabling Smart+Connected Communities (Smart+Connected Communities Institute, 2012) <http://www.smartconnectedcommunities.org/docs/DOC-2150> Accessed January 4, 2013.

M. Angelidou, "Smart City Policies: A Spatial Approach," Cities: The International Journal of Urban Policy and Planning 41:Supplement 1 (2014) S3-S11.

A. Anttiroiko, "U-cities Reshaping Our Future: Reflections on Ubiquitous Infrastructure as an Enabler of Smart Urban Development," AI \& SOCIETY: Journal of Knowledge, Culture and Communication 28:4 (2013) 491-507.

L. Atzori, A. Iera, and G. Morabito, "The Internet of Things: A Survey," Computer Networks 54:15 (2010) 2787-2805.

M. Batty, "The Computable City," International Planning Studies 2:2 (1997) 155-173.

M. Batty, The New Science of Cities (Cambridge, MA: The MIT Press, 2014).

M. Batty and S. Marshall, "The Evolution of Cities: Geddes, Abercrombie and the New Physicalism," Town Planning Review 80:6 (2009) 551-574.

J. Belissent, C. Mines, E. Radcliffe, and Y. Darashkevich, Getting Clever About Smart Cities: New Opportunities Require New Business Models (Cambridge, MA: Forrester Research, 2010) $<$ http://www.forrester.com/Getting+Clever+About+Smart+Cities+New+Opportunities +Require+New+Business+Models/fulltext/-/E-RES56701> Accessed March 30, 2012.

N. De Bellis, Bibliometrics and Citation Analysis: From the Science Citation Index to 
Cybermetrics (Lanham, MD: The Scarecrow Press, 2009).

L. Benevolo, La Fine della Città (Rome: Laterza, 2011).

R. Bolici and L. Mora, "Urban Regeneration in the Digital Era: How to Develop Smart City Strategies in Large European Cities," TECHNE: Journal of Technology for Architecture and Environment 5:2 (2015) 110-119.

A. Caragliu, C. Del Bo, and P. Nijkamp, "Smart Cities in Europe," paper presented at 3rd Central European Conference in Regional Science (Kosice, 7-9 October 2009).

A. Caragliu, C. Del Bo, and P. Nijkamp, "Smart Cities in Europe," Journal of Urban Technology 18:2 (2011) 65-82.

M. Castells, The Rise of the Network Society (Oxford: Balckwell Publishing Ltd, 1996).

H. Chourabi, T. Nam, S. Walker, R.J. Gil-Garcia, S. Mellouli, K. Nahon, T.A. Pardo, and H.J. Scholl, "Understanding Smart Cities: An Integrative Framework," in R.H. Sprague, ed., Proceedings of the 45th Hawaii International Conference on System Sciences (HICSS) (Piscataway, NJ: IEEE, 2012) 2289-2297.

E. Christopoulou, D. Ringas, and J. Garofalakis, "The Vision of the Sociable Smart City," in N. Streitz and P. Markopoulos, eds., Distributed, Ambient, and Pervasive Interactions: Second International Conference, DAPI 2014, Held as Part of $\mathrm{HCl}$ International 2014, Heraklion, Crete, Greece, June 22-27, 2014. Proceedings (Berlin: Springer, 2014) 545-554.

A. Cocchia and P. Damieri, "Exploring Smart City Vision by University, Industry and Government," in F. D'Ascenzo, M. Magni, A. Lazazzara, and S. Za, eds., Blurring the Boundaries Through Digital Innovation: Individual, Organizational, and Societal Challenges (Berlin: Springer, 2016) 259-270.

A. Coe, G. Paquet, and J. Roy, "E-governance and Smart Communities: A Social Learning Challenge," Social Science Computer Review - The Digital Imperative of Social Sciences in the New Millenium 19:1 (2001) 80-93.

G. Concilio and F. Rizzo, eds., Human Smart Cities: Rethinking the Interplay Between Design and Planning (Berlin: Springer, 2016).

M. Deakin, ed., Smart Cities: Governing, Modelling and Analysing the Transition (New York City, NY: Routledge, 2014).

M. Deakin and H. Al Wear, "From Intelligent to Smart Cities," Intelligent Buildings International 3:3 (2011) 140-152.

M. de Jong, S. Joss, D. Schraven, C. Zhan, and M. Weijnen, "Sustainable-SmartResilient-Low Carbon-Eco-Knowledge Cities; Making Sense of a Multitude of Concepts Promoting Sustainable Urbanization," Journal of Cleaner Production 109 (2015) 25-38.

Y. Ding, G.G. Chowdhury, and S. Foo, "Bibliometric Cartography of Information Retrieval Research by Using Co-Word Analysis," Information Processing and Management 37:6 (2001) 817-842.

S. Dirks, C. Gurdgiev, and M. Keeling, Smarter Cities for Smarter Growth: How Cities Can Optimize Their Systems for the Talent-based Economy (Somers, NY: IBM Corporation,

2010) <http://public.dhe.ibm.com/common/ssi/ecm/en/gbe03348usen/GBE03348USEN.P DF> Accessed February 3, 2012.

S. Dirks and M. Keeling, A Vision of Smarter Cities: How Cities Can Lead the Way into a Prosperous and Sustainable Future (Somers, NY: IBM Corporation, 2009) $<$ http://www-03.ibm.com/press/attachments/IBV_Smarter_Cities_-_Final.pdf> Accessed February 3, 2012.

S. Dirks, M. Keeling, and J. Dencik, How Smart is Your City: Helping Cities Measure Progress (Somers, NY: IBM Corporation, 2009) <http://public.dhe.ibm.com/common/ssi/ecm/en/gbe03248usen/GBE03248USEN.P DF> Accessed June 6, 2014.

A. Durán-Sánchez, M. de la Cruz del Río-Rama, A. Sereno-Ramírez, and K. Bredis, "Sustainability and Quality of Life in Smart Cities: Analysis of Scientific Production," 
in M. Peris-Ortiz, D.R. Bennett, \& D. Pérez-Bustamante Yábar, eds., Sustainable Smart Cities: Creating Spaces for Technological, Social and Business Development (Cham: Springer, 2017) 159-181.

A. D'Auria, M. Tregua, and F. Bifulco, "From Digital City to Smart City: Different Perspectives Overlapping or Misinterpreted?," in M. Mokrys, S. Badura, and A. Lieskovsky, eds., Proceedings of the 2nd International Global Virtual Conference (GV-Conf 2014) (Zilina: EDIS - Publishing Institution of the University of Zilina, 2014) 603-608.

V. Fernandez-Anez, "Stakeholders Approach to Smart Cities: A Survey on Smart City Definitions," in E. Alba, F. Chicano, and G. Luque, eds., Smart Cities. First International Conference, Smart-CT 2016, Málaga, Spain, June 15-17, 2016, Proceedings (Berlin: Springer, 2016) 157-167.

R.J. Firmino, Defining and Understanding the Virtual Cities Phenomenon: Briefing Document (Salford: University of Salford, 2003) $<$ https://www.academia.edu/977988/Defining_and_understanding_the_virtual_cities phenomenon_Briefing_document> Accessed October 3, 2012.

T.M.J. Fruchterman and E.M. Reingold, "Graph Drawing by Force-directed Placement," Software-practice and experience 21:11 (1991) 1129-1164.

E. Garfield, "Citation Indexing for Studying Science," Information Scientist 1:15 (1970) 133-138.

D.V. Gibson, G. Kozmetsky, and R.W. Smilor, eds., The Technopolis Phenomenon: Smart Cities, Fast Systems, Global Networks (Lanham, MD: Rowman \& Littlefield Publishers, 1992).

R. Giffinger, C. Ferter, H. Kramar, R. Kalasek, N. Pichler-Milanović, and E. Meijers,, Smart Cities: Ranking of European Medium-sized Cities (Vienna: Vienna University of Technology - Centre of Regional Science (SRF), 2007) <http://www.smartcities.eu/download/smart_cities_final_report.pdf> Accessed May 9, 2012.

B. Godin, "On the Origins of Bibliometrics," Scientometrics 68:1 (2006) 109-133.

S. Graham, "Telecommunications and the Future of Cities: Debunking the Myths," Cities: The International Journal of Urban Policy and Planning 14:1 (1997) 21-29.

S. Graham, "Introduction: Cities and Infrastructure Networks," International Journal of Urban and Regional Research 24:1 (2000) 114-119.

S. Graham, "Information Technologies and Reconfigurations of Urban Spaces," International Journal of Urban and Regional Research 25:2 (2001) 405-410.

S. Graham, "Bridging Urban Digital Divides? Urban Polarisation and Information and Communications Technologies (ICTs)," Urban Studies 39:1 (2002) 33-56.

S. Graham, ed., The Cybercities Reader (New York City, NY: Routledge, 2004a).

S. Graham, "Introduction: From Dreams of Transcendence to the Remediation of Urban Life," in S. Graham, ed., The Cybercities Reader (New York, United States: Routledge, 2004b) 1-29.

S. Graham and S. Marvin, "Planning Cyber-cities? Integrating Telecommunications into Urban Planning," in S. Graham, ed., The Cybercities Reader (New York City, NY: Routledge, 2004) 341-347.

S. Graham and S. Marvin, Telecommunications and the City: Electronic Spaces, Urban Places (New York City, NY: Routledge, 1996).

S. Graham and S. Marvin, "Planning Cyber-cities? Integrating Telecommunications Into Urban Planning," Town Planning Review 70:1 (1999) 89-114.

S. Graham and S. Marvin, Splintering Urbanism: Networked Infrastructures, Technological Mobilities and the Urban Condition (New York City, NY: Routledge, 2001).

I. Greco and A. Cresta, "A Smart Planning for Smart City: The Concept of Smart City as an Opportunity to Re-think the Planning Models of the Contemporary City," in O. Gervasi, B. Murgante, S. Misra, M.L. Gavrilova, A.M. Alves Coutinho Rocha, C. Torre, D. Taniar, and B.O. Apduhan, eds., Computational Science and Its 
Applications - ICCSA 2015: 15th International Conference, Banff, AB, Canada, June 22-25, 2015, Proceedings, Part II (Berlin: Springer, 2015) 563-576.

R.E. Hall, B. Bowerman, J. Braverman, J. Taylor, H. Todosow, and U. von Wimmersperg, "The Vision of a Smart City," paper presented at 2nd International Life Extension Technology Workshop (Paris, 28 September 2000).

D. Hemment and A. Townsend, eds., Smart Citizens (Manchester: FutureEverything, 2013).

J.M. Hernández-Muñoz, J. Bernat Vercher, L. Muñoz, J.A. Galache, M. Presser, L.A. Hernández Gómez, and J. Pettersson, "Smart Cities at the Forefront of the Future Internet," in J. Domingue, A. Galis, A. Gavras, T. Zahariadis, D. Lambert, F. Cleary, P. Daras, S. Krco, H. Muller, M. Li, H. Schaffers, V. Lotz, F. Alvarez, B. Stiller, S. Karnouskos, S. Avessta, and M. Nillson, eds., The Future Internet. Future Internet Assembly 2011: Achievements and Technological Promises (Berlin: Springer, 2011) 447-462.

R.G. Hollands, "Will the Real Smart City Please Stand Up?" City: Analysis of Urban Trends, Culture, Theory, Policy, Action 12:3 (2008) 303-320.

R.G. Hollands, "Critical Interventions into the Corporate Smart City," Cambridge Journal of Regions, Economy and Society 8:1 (2015) 61-77.

R.G. Hollands, "Beyond the Corporate Smart City? Glimpses of Other Possibilities of Smartness," in S. Marvin, A. Luque-Ayala, and C. McFarlane, eds., Smart Urbanism: Utopian Vision or False Dawn? (New York City, NY: Routledge, 2016) 168-184.

G.R. Hutton, "Scientific Grey Literature in a Digital Age: Measuring Its Use and Influence in an Evolving Information Economy" paper presented at 37th Annual Conference of the Canadian Association of Information Science \& Inaugural Librarians' Research Institute Symposium. Mapping the 21st Century Information Landscape: Borders, Bridges and Byways (Ottawa, 28-30 May 2009).

T. Jacobsen, R.L. Punzalan, and M.L. Hedstrom, "Invoking Collective Memory: Mapping the Emergence of a Concept in Archival Science," Archivial Science 13:2-3 (2013) 217-251.

J. Kamalski and A. Kirby, "Bibliometrics and Urban Knowledge Transfer," Cities: The International Journal of Urban Policy and Planning 29:Supplement 2 (2012) S3-S8.

S. Karnouskos and T. Nass de Holanda, "Simulation of a Smart Grid City with Software Agents," in EMS '09: Third UKSim European Symposium on Computer Modeling and Simulation (Piscataway, NJ: Institute of Electrical and Electronics Engineers (IEEE), 2009) 424-429.

R. Kitchin, "The Real-time City? Big Data and Smart Urbanism," GeoJournal 79:1 (2014) 1-14.

N. Komninos, Intelligent Cities: Innovation, Knowledge, Systems and Digital Spaces (New York City, NY: Spon Press, 2002).

N. Komninos, "The Architecture of Intelligent Cities: Integrating Human, Collective and Artificial Intelligence to Enhance Knowledge," in Proceedings of the 2nd IET International Conference on Intelligent Environments (Norwich: Page Bros Ltd, 2006) 13-20.

N. Komninos, Intelligent Cities and Globalization of Innovation Networks (New York City, NY: Routledge, 2008).

N. Komninos, The Age of Intelligent Cities: Smart Environments and Innovation-for-all Strategies (New York City, NY: Routledge, 2014).

G.C. Lazaroiu and M. Roscia, "Definition Methodology for the Smart Cities Model," Energy 47:1 (2012) 326-332.

J. Lee, M.G. Hancock, and M. Hu, "Towards an Effective Framework for Building Smart Cities: Lessons From Seoul and San Francisco," Technological Forecasting and Social Change 89 (2014) 80-99.

Z. Liu, "Visualizing the Intellectual Structure in Urban Studies: A Journal Co-citation 
Analysis (1992-2002)," Scientometrics 62:3 (2005) 385-402.

H. Martin and T. Daim, "Technology Roadmapping Through Intelligence Analysis: Case of Nanotechnology," International Journal of Society Systems Science 1:1 (2008) 49-65.

D. McNeill, "IBM and the Visual Formation of Smart Cities," in S. Marvin, A. LuqueAyala, and C. McFarlane, eds., Smart Urbanism: Utopian Vision or False Dawn? (New York City, NY: Routledge, 2016) 34-51.

W.J. Mitchell, The City of Bits: Space, Place, and the Infobahn (Cambridge, MA: The MIT Press, 1995).

W.J. Mitchell, E-topia: Urban Life, Jim--but Not as We Know It (Cambridge, MA: The MIT Press, 1999).

W.J. Mitchell, Me++: The Cyborg Self and the Networked City (Cambridge, MA: The MIT Press, 2003).

R. Moss Kanter and S.S. Litow, Informed and Interconnected: A Manifesto for Smarter Cities (Boston, MA: Harvard Business School, 2009) <http://www.hbs.edu/faculty/Publication\%20Files/09-141.pdf> Accessed January 24, 2012.

F. Moya-Anegon, B. Vargas-Quesada, V. Herrero-Solana, Z. Chinchilla-Rodriguez, E. Corera-Alvarez, and F.J. Munoz-Fernandez, "A New Technique for Building Maps of Large Scientific Domains Based on the Cocitation of Classes and Categories," Scientometrics 61:1 (2004) 129-145.

M. Naphade, G. Banavar, C. Harrison, J. Paraszczak, and R. Morris, "Smarter Cities and Their Innovation Challenges," Computer 44:6 (2011) 32-39.

N. Odendaal, "Information and Communication Technology and Local Governance: Understanding the Difference Between Cities in Developed and Emerging Economies," Computers, Environment and Urban Systems 27:6 (2003) 585-607.

A. Ojo, Z. Dzhusupova, and E. Curry, "Exploring the Nature of the Smart Cities Research Landscape," in J.R. Gil-Garcia, T.A. Pardo, and T. Nam, eds., Smarter As the New Urban Agenda: A Comprehensive View of the 21st Century City (Berlin: Springer, 2016) 23-47.

S. Paroutis, M. Bennett, and L. Heracleous, "A Strategic View on Smart City Technology: The Case of IBM Smarter Cities During a Recession," Technological Forecasting and Social Change 89 (2014) 262-272.

H. Partridge, "Developing a Human Perspective to the Digital Divide in the Smart City," paper presented at ALIA 2004 Biennial Conference: Challenging Ideas (Gold Coast, 21-24 September 2004).

K.A. Paskaleva, "Enabling the Smart City: The Progress of City E-governance in Europe," International Journal of Innovation and Regional Development 1:4 (2009) 405-422.

K.A. Paskaleva, "The Smart City: A Nexus for Open Innovation?," Intelligent Buildings International 3:3 (2011) 133-152.

A. Pritchard, "Statistical Bibliography or Bibliometrics?," Journal of Documentation 25:4 (1969) 348-349.

F. Ricciardi and S. Za, "Smart City Research as an Interdisciplinary Crossroads: A Challenge for Management and Organization Studies," in L. Mola, F. Pennarola, \& S. Za, eds., From Information to Smart Society: Environment, Politics and Economics (Cham: Springer, 2015) 163-171.

H. Schaffers, N. Komninos, M. Pallot, M. Aguas, E. Almirall, T. Bakici, J. Barroca, D. Carter, M. Corriou, J. Fernadez, H. Hielkema, A. Kivilehto, M. Nilsson, A. Oliveira, E. Posio, A. Sällström, R. Santoro, B. Senach, I. Torres, P. Tsarchopoulos, B. Trousse, P. Turkama, and J. Lopez Ventura, Smart Cities as Innovation Ecosystems Sustained by the Future Internet (2012) <http://hal.archivesouvertes.fr/docs/00/76/96/35/PDF/FIREBALL-White-Paper-Final2.pdf> Accessed August 24, 2011. 
H. Schaffers, N. Komninos, M. Pallot, B. Trousse, M. Nilsson, and A. Oliveira, "Smart Cities and the Future Internet: Towards Cooperation Frameworks for Open Innovation," in J. Domingue, A. Galis, A. Gavras, T. Zahariadis, D. Lambert, F. Cleary, P. Daras, S. Krco, H. Muller, M. Li, H. Schaffers, V. Lotz, F. Alvarez, B. Stiller, S. Karnouskos, S. Avessta, and M. Nillson, eds., The Future Internet. Future Internet Assembly 2011: Achievements and Technological Promises (Berlin: Springer, 2011) 431-446.

J. Schopfel and D.J. Farace, "Grey Literature," in M.J. Bates and M.N. Maack, eds., Encyclopedia of Library and Information Sciences (New York City, NY: Taylor \& Francis, 2010) 2029-2039.

J. Schopfel, "Towards a Prague Definition of Grey Literature," in D.J. Farace and J. Fratzen, eds., Twelfth International Conference on Grey Literature: Transparency in Grey Literature. Grey Tech Approaches to High Tech Issues (Amsterdam: TextRelease, 2010) 11-26.

B. Secchi, La Città del Ventesimo Secolo (Bari: Laterza, 2011).

J.M. Shapiro, Smart Cities: Quality of Life, Productivity, and the Growth Effects of Human Capital (Cambridge, MA: National Bureau of Economic Research, 2005) <http://www.nber.org/papers/w11615> Accessed February 21, 2011.

W. Shiau and Y.K. Dwivedi, "Citation and Co-citation Analysis to Identify Core and Emerging Knowledge in Electronic Commerce Research," Scientometrics 94:3 (2013) 1317-1337.

D. Shin, "A Critique of Korean National Information Strategy: Case of National Information Infrastructures," Government Information Quarterly 24:3 (2007) 624645.

D. Shin, "Ubiquitous City: Urban Technologies, Urban Infrastructure and Urban Informatics," Journal of Information Science 35:5 (2009) 515-526.

D. Shin, "A Realization of Pervasive Computing: Ubiquitous City," in D.F. Kocaoglu, T.R. Anderson, and T.U. Daim, eds., 2010 Proceedings of PICMET '10: Technology Management for Global Economic Growth (Piscataway, NJ: Institute of Electrical and Electronics Engineers (IEEE), 2010) 1-10.

S.T. Shwayri, "A Model Korean Ubiquitous Eco-city? The Politics of Making Songdo," Journal of Urban Technology 20:1 (2013) 39-55.

H.G. Small, "Co-citation in the Scientific Literature: A New Measure of the Relationship Between Two Documents," Journal of the American Society for Information Science and Technology 24:4 (1973) 265-269.

H.G. Small, "Cited Documents as Concept Symbols," Social Studies of Science 8:3 (1978) 327-340.

H.G. Small and D. Crane, "Specialties and Disciplines in Science and Social Science: An Examination of Their Structure Using Citation Indexes," Scientometrics 1:5-6 (1979) 445-461.

H.G. Small and B.C. Griffith, "The Structure of Scientific Literature I: Identifying and Graphing Specialties," Science Studies 4:1 (1974) 17-40.

O. Soderstrom, T. Paasche, and F. Klauser, "Smart Cities as Corporate Storytelling," City: Analysis of Urban Trends, Culture, Theory, Policy, Action 18:3 (2014) 307-320.

H. Tamai, "Fujitsu's Approach to Smart Cities," FUJITSU Scientific \& Technical Journal 50:2 (2014) 3-10.

The Climate Group, SMART 2020: Enabling the Low Carbon Economy in the Information Age (The Climate Group, 2008) <http://www.smart2020.org/_assets/files/02_Smart2020Report.pdf> Accessed June $5,2014$.

R.J.W. Tijssen and T.N. van Leeuwen, Extended Technical Annex to Chapter 5 of the 'Third European Report on S\&T Indicators': Bibliometric Analyses of World Science (Leiden: Leiden University, <ftp://ftp.cordis.europa.eu/pub/indicators/docs/3rd_report_biblio_ext_methodology.p 
df> Accessed June 13, 2014.

A. Townsend, Smart Cities: Big Data, Civic Hackers, and the Quest for a New Utopia (New York City, NY: W.W. Norton \& Company Ltd, 2013).

M. Tregua, A. D'Auria, and F. Bifulco, "Comparing Research Streams on Smart City and Sustainable City," China-USA Business Review 14:4 (2015) 203-215.

G. Urzaiz, R. Hervas, J. Fontecha, and J. Bravo, "A High-level Model for a Healthy Smart City," in L. Pecchia, L. Luke Chen, C. Nugent, and J. Bravo, eds., Ambient Assisted Living and Daily Activities: 6th International Work-Conference, IWAAL 2014, Belfast, UK, December 2-5, 2014. Proceedings (Berlin: Springer, 2014) 386389.

D. Washburn, S. Usman, S. Balaouras, R.A. Dines, N.M. Hayes, and L.E. Nelson, Helping CIOs Understand "Smart City" Initiatives (Cambridge, MA: Forrester Research, 2010) $<$ http://www.forrester.com/Helping+ClOs+Understand+Smart+City+Initiatives/quicks can/-/E-RES55590> Accessed March 20, 2012.

M. Wolfram, "Deconstructing Smart Cities: An Intertextual Reading of Concepts and Practices for Integrated Urban and ICT Development," in M. Schrenk, V.V. Popovich, P. Zeile, and P. Elisei, eds., Proceedings REAL CORP 2012. 17th International Conference on Urban Planning, Regional Development and Information Society. Re-mixing the City: Towards Sustainability and Resilience (Wien: Competence Center of Urban and Regional Planning (CORP), 2012) 171181.

T. Yigitcanlar, Technology and the City: Systems, Applications and Implications (New York City, NY: Routledge, 2016).

T. Yigitcanlar and S.H. Lee, "Korean Ubiquitous-eco-city: A Smart-sustainable Urban Form or a Branding Hoax?," Technological Forecasting \& Social Change 89 (2014) 100-114.

A. Zanella, N. Bui, A. Castellani, L. Vangelista, \& M. Zorzi, "Internet of Things for Smart Cities," IEEE Internet of Things Journal 1:1 (2014) 22-32.

S. Zygiaris, "Smart City Reference Model: Assisting Planners to Conceptualize the Building of Smart City Innovation Ecosystems," Journal of the Knowledge Economy 4:2 (2013) 217-231. 